\title{
EFFECT OF LOW CARBON ECONOMY ON ENTERPRISE COMPETITIVENESS: A MULTIPLE MEDIATION MODEL
}

\author{
ZHANG, H. W. \\ School of Economics and Management, Beijing JiaoTong University, Beijing 10044, China \\ (e-mail: 16241267@bjtu.edu.cn)
}

(Received $8^{\text {th }}$ Mar 2019; accepted $1^{\text {st }}$ May 2019)

\begin{abstract}
The low-carbon economy is an economic model based on low energy consumption, low pollution and low emissions. According to some research, a low-carbon economy model can have a significant impact on a company's competitiveness. However, there are two different types of views on the relationship between environmental regulation and corporate competitiveness. This study uses a method of testing multiple mediations that can explain many complex internal mechanisms in the field of organizational behavior science. The results show that the low carbon economy has a positive effect on technology innovation, and this effect will influence enterprise competitiveness through sustainable development. We also found that the compound multiple mediation model has an advantage in explaining the problems involved with low carbon economy and enterprise competitiveness.
\end{abstract}

Keywords: low energy consumption, sustainable development, $\mathrm{CO}_{2}$ emissions, technology innovation, enterprise strategic

\section{Introduction}

Low-carbon development is a strategic decision that human beings have to face and seek opportunities under the dual pressure of financial crisis and climate and environmental crisis (Louche et al., 2019; Gong, et al., 2018). It will bring about a series of fundamental changes in the whole economy, society and enterprises. It is not an exaggeration to call it a technological revolution or an industrial revolution. The arrival of the low-carbon era will lead to profound changes in the standards of our enterprises, including value standards and evaluation systems (Niamir et al., 2018). Opportunities of emerging industrial revolution brewing under the development mode of low-carbon economy urgently need the strong support of enterprise strategic planning and thus promote the economic development mode from a high carbon economy to low carbon economy (Barron et al., 2018; Du, et al., 2018).

Low-carbon economy refers to an economic development pattern that achieves a winwin situation for economic and social development and ecological environmental protection (Shimada et al., 2007). Under the guidance of the concept of sustainable development, through technical innovation, system innovation, industrial transformation, new energy development and other means to reduce the high carbon energy consumption of coal, oil, greenhouse gas emissions and so on (Hu et al., 2011). With the increase of the global population and the continued economic growth, the environmental problems and consequences caused by the use of fossil energy and other conventional sources have received more and more attention. Environmental hazards such as exhaust gas pollution, photochemical smog, water pollution and acid rain, as well as global climate change caused by the rise of carbon dioxide concentration in the atmosphere, will cause serious consequences (Foxon, 2011). Therefore, a series of new concepts and policies have emerged, such as carbon footprint, low-carbon economy, low-carbon technology, lowcarbon development, low-carbon lifestyle, low-carbon society, low-carbon city and a lowcarbon world (Nader, 2009; Liu, 2018; Lefevre et al., 2018; Ervine, 2018). 
The arrival of the low-carbon era will lead to profound changes in the standards of our enterprises, including value standards and evaluation systems. Under the guidance of lowcarbon economic policies, enterprises must shift from the traditional growth model to directly applying the new century's innovative technology and innovation mechanism and achieving sustainable social development through low-carbon economic model and lifestyle (Tavoni et al., 2012; Li and Sun, 2018; Ropeik, 2017). Opportunities of emerging industrial revolution brewing under the development mode of low-carbon economy urgently need the strong support of enterprise strategic planning and thus promote the economic development mode from a high carbon economy to low carbon economy. From this perspective, the low-carbon economy is both a limitation and an opportunity. Therefore, this study mainly explores the effect of the low-carbon economy on enterprise competitiveness and uses a method of multiple mediation models to reveal the internal mechanism.

\section{Research background and hypotheses}

\section{Low carbon economy}

The low-carbon economy is an economic model based on low energy consumption, low pollution, and low emissions. The essence of the low-carbon economy is the problem of high energy utilization efficiency and clean energy structure. In the context of global warming, the low-carbon revolution with energy efficiency and low emissions as the core is gradually changing many industrial ecosystems. Therefore, companies must focus on developing low-carbon technologies to seize the opportunities and industry commanding heights.

Tavoni et al. (2012) believe that with the increase in income, the industrial and consumption structures have changed. At the same time, when people began to pay attention to the issue of protecting the environment, the phenomenon of environmental degradation gradually slowed down or even disappeared. Glaser (2003) concluded that $\mathrm{CO}_{2}$ emissions are in an "N" rather than inverted "U" relationship with economic growth. Smale et al. (2006) believe that in the early stage of industrialization, with the development of the economy and the increase of per capita income, the per capita $\mathrm{CO}_{2}$ emissions will be at a higher level.

\section{Low-carbon economy and enterprise competitiveness}

There are two different types of views on the relationship between environmental regulation and corporate competitiveness. The first perspective is that the implementation of environmental regulations will lead to a decline in the competitiveness of enterprises. The government implements environmental regulations and companies need to add special costs to eliminate pollution and reduce their environmental impact to meet environmental standards. The environmental standards require that the production costs of enterprises will rise sharply, which will directly affect their competitiveness. Healy and Barry (2017) argued that environmental regulation is not only not conducive to technological innovation, but because the entire process of environmental control will cause companies to be forced to transform the original production process, which will have an impact on technological innovation. Garay and Font (2012) pointed out that in order to adapt to environmental regulations, the company's processes are becoming more and more complex, resulting in a large management difficulty, and the management costs 
are increasing, eventually resulting in a decline in corporate profits and a decline in competitiveness. Ortiz et al. (2009) showed that as environmental governance costs increase, it is increasingly difficult for individual companies to achieve a win-win situation for both environment and competitiveness. The stricter environmental regulations will inevitably worsen the business conditions of enterprises. At the same time, the benefits of adopting new technologies are not enough to boost the profits of enterprises. While environmental protection regulation improves the overall social welfare, it will lead to a decline in industrial production efficiency, and enterprises pay a higher price for it.

However, other scholars believe that companies will actively seek environmental technology innovation and develop environmental products in response to environmental policies, competitors and consumers (Rijsberman, 2017; Ervine, 2018). As a result, the sustainability of the industry will naturally increase, thus causing the competitiveness to transform and transition around the green. From a dynamic perspective, strict environmental standards will encourage companies to accelerate the pace of product innovation, and encourage enterprises to continuously improve the inefficiency in the production process, and reluctantly. The effective use of resources, through continuous technological innovation, brings about a reduction in pollution and an increase in output, resolving the contradiction between the environment and competitiveness, and achieving a win-win situation in which both economic performance and environmental performance are simultaneously changed. At the same time, this technological innovation will also enable companies that comply with environmental standards to gain a "first mover advantage". Managers should take environmental improvement as an opportunity to add economic value and competitive advantage, and should not only be an annoying cost or threat. Based on this, this paper proposes:

H: Low carbon economy influence enterprise competitiveness through a multiple mediation model, see in Figure 1.

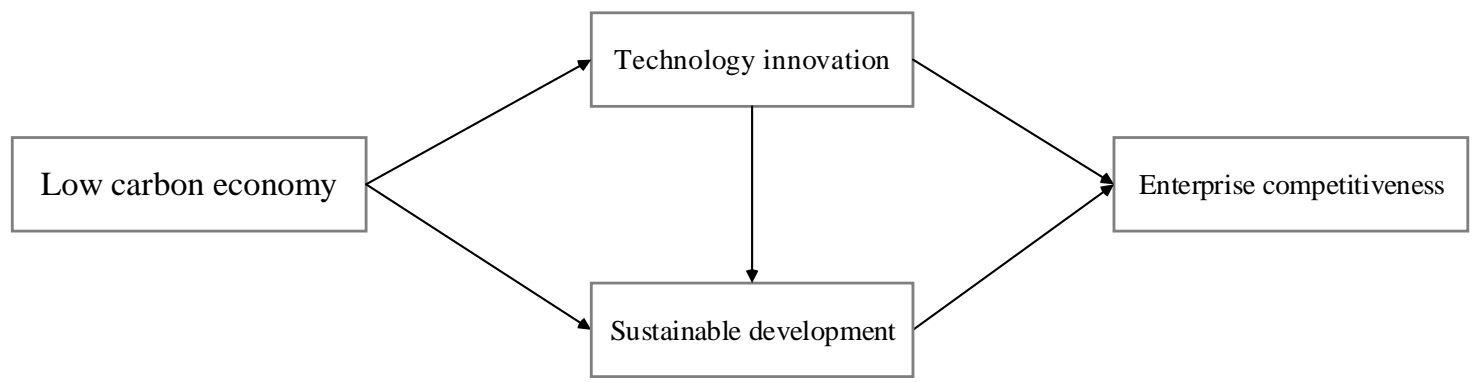

Figure 1. Theory research model

\section{Methodology}

\section{Sample source}

In this paper, we used the multiple mediation models to analyze the relationship between low carbon economy and enterprise competitiveness. First, we selected 42 enterprises in China and got their basic information before the investigation. Then, during the investigation, the managers answered a 20-question questionnaire including all the indicators of this study. The descriptive statistics are in Table 1. 
Table 1. Descriptive statistics $(n=42)$

\begin{tabular}{c|c|c|c|c}
\hline Variable & $\begin{array}{c}\text { Low carbon } \\
\text { economy }\end{array}$ & $\begin{array}{c}\text { Technology } \\
\text { innovation }\end{array}$ & $\begin{array}{c}\text { Sustainable } \\
\text { development }\end{array}$ & $\begin{array}{c}\text { Enterprise } \\
\text { competitiveness }\end{array}$ \\
\hline Low carbon economy & 1 & & & \\
Technology innovation & $.639^{* *}$ & 1 & & \\
Sustainable development & $.674^{* *}$ & $.751^{* *}$ & 1 & 1 \\
Enterprise competitiveness & $.641^{* *}$ & $.691^{* *}$ & $.706^{* *}$ & \\
\hline
\end{tabular}

$* *$ Correlation is significant at the 0.01 level (double tail)

\section{Multiple mediation model}

\section{Ordinary least squares mediation model}

The ordinary least squares (OLS) mediation model always present in the form of three regression equations (Preacher and Hayes, 2008):

$$
\begin{gathered}
y_{i}=\beta_{01}+\tau x_{i}+\varepsilon_{1 i} \\
m_{i}=\beta_{02}+\alpha x_{i}+\varepsilon_{2 i} \\
y_{i}=\beta_{03}+\beta m_{i}+\tau^{`} x_{i}+\varepsilon_{3 i}
\end{gathered}
$$

In these equations (Eqs. 1-3), $\mathrm{y}_{\mathrm{i}}$ is the dependent variable, $\mathrm{m}_{\mathrm{i}}$ is the mediating variable, and $x_{i}$ is the independent variable. The coefficient between the independent variable and the dependent variable is represented by $\tau$, and $\tau^{\prime}$ is the coefficient adjusted for the influence of the mediating variable. $\beta_{01}, \beta_{02}$, and $\beta_{03}$ represent the intercept in the three equations.

To calculate the multiple mediation effects, there are three points to lay the foundation. First, $\beta$ in the third equation is relating to the dependent variable and the mediating variable. Second, $\alpha_{\mathrm{i}}$ in the second equation is relating to the independent variable and the mediating variable. Third, the product of $\alpha$ and $\beta$ is the estimator of the indirect effect, and $\tau^{\prime}$ is the estimator of the direct effect.

The variance of the indirect effect $\sigma_{\alpha \beta}^{2}$ is based on the variance of $\alpha$ and $\beta$, and it is derived using a second-order Taylor series in Equation 4:

$$
\sigma_{\alpha \beta}^{2}=\alpha^{2} \sigma_{\beta}^{2}+\beta^{2} \sigma_{\alpha}^{2}+\sigma_{\alpha}^{2} \sigma_{\beta}^{2}
$$

If $\alpha$ and $\beta$ are nonzero values, according to Monte Carlo studies, for a sample size of 100 or more in a simulation model, all three variance estimators appear to have a relative bias of less than 5\%. So Confidence limits are constructed in Equation 5:

$$
\alpha \beta \pm z_{1-\omega / 2} \times \sigma_{\alpha \beta}
$$

where $z_{1-\omega / 2}$ is the value on the $\mathrm{z}$-distribution corresponding to the desired Type I error rate, $\omega$. 
As the indirect effect is the product of $\alpha$ and $\beta$, and the estimates are normally distributed. The distribution of the product is an index to test the indirect effect. In other words, we can test the indirect effect based on $z_{\alpha} z_{\beta}$, where $z_{\alpha}=\alpha / \sigma_{\alpha}$ and $z_{\beta}=\alpha / \sigma_{\beta}$.

The central moments of the process are as follows (Eqs. 6-9).

$$
\begin{gathered}
\text { Mean }: M_{1}=\mu=z_{\alpha} z_{\beta} \\
\text { Variance }: M_{2}=\sigma^{2}=z_{\alpha}^{2}+z_{\beta}^{2}+1 \\
\text { Skewness : } M_{3}=\alpha_{3}=\frac{6\left(z_{\alpha} z_{\beta}\right)}{\left(z_{\alpha}^{2}+z_{\beta}^{2}+1\right)^{3 / 2}} \\
\text { Kurtosis : } M_{4}=\alpha_{4}=\frac{12\left(z_{\alpha}^{2}+z_{\beta}^{2}\right)+6}{\left(z_{\alpha}^{2}+z_{\beta}^{2}+1\right)^{2}}
\end{gathered}
$$

To get the analytical solution, a Bessel function with a purely imaginary argument is used in Equation 10.

$$
\begin{aligned}
f\left(z_{\alpha} z_{\beta}\right) & =\frac{e^{-\left(z_{\alpha}^{2}+z_{\beta}^{2}\right) / 2}}{\pi}\left[\sum_{0} K_{0}+\left(z_{\alpha}^{2}+z_{\beta}^{2}\right) \frac{z_{\alpha} z_{\beta}}{2 !} \sum_{2} K_{I}\right. \\
& +\left(z_{\alpha}^{4}+z_{\beta}^{4}\right) \frac{\left(z_{\alpha} z_{\beta}\right)^{2}}{4 !} \sum_{4} K_{2} \\
& \left.+\left(z_{\alpha}^{6}+z_{\beta}^{6}\right) \frac{\left|z_{\alpha} z_{\beta}\right|^{3}}{6 !} \sum_{6} K_{3}+\ldots\right]
\end{aligned}
$$

In the equation, $\mathrm{K}$ is the Bessel function and $\Sigma$ is a Laurent series in Equation 11.

$$
\sum_{r}\left(z_{\alpha}, z_{\beta}, z_{\alpha} z_{\beta}\right)=1+\frac{z_{\alpha} z_{\beta} z_{\alpha} z_{\beta}}{r+1}+\frac{\left(z_{\alpha} z_{\beta} z_{\alpha} z_{\beta}\right)^{2}}{(r+1)^{2} 2 !}+\frac{\left(z_{\alpha} z_{\beta} z_{\alpha} z_{\beta}\right)^{3}}{(r+1)^{3} 3 !}+\ldots
$$

In the equation, $\mathrm{r}$ is the order of the Laurent series in Equation 12.

$$
(r+k)^{k}=(r+k)(r+k-1) \ldots(r+1)
$$

To calculate the 95\% standard normal confidence limits, it used a Standardized Critical Value (SCV). According to Meeker's suggestion (Meeker et al., 1982), it found the Critical Value (CV) in the table, and then convert to the standardized metric of the regression coefficient ( $\alpha$ and $\beta$ ) in Equation 13. 


$$
S C V=\frac{C V-z_{\alpha} z_{\beta}}{\sqrt{z_{\alpha}^{2}+z_{\beta}^{2}+1}}
$$

\section{Parallel multiple mediation model}

Parallel multiple mediation model reflects a situation in which multiple variables simultaneously mediate between the independent and dependent variable, see in Figure 2.

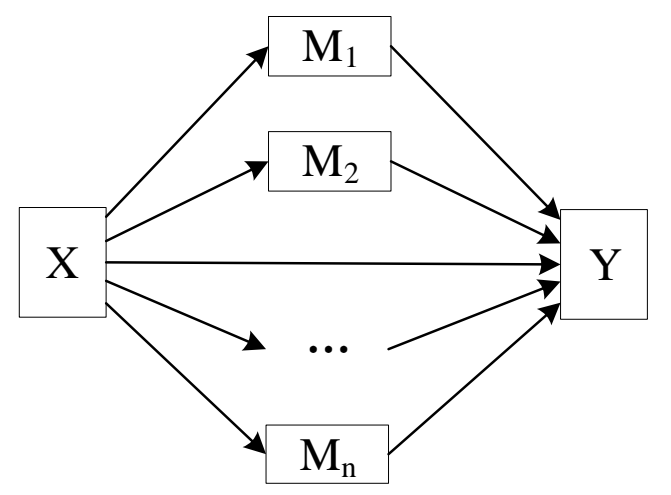

Figure 2. Parallel multiple mediations model

The relationship between the dependent variables, independent variables and multiple mediating variables are as follows (Eqs. 14-16).

$$
\begin{gathered}
Y=\tau X+\varepsilon_{X} \\
M_{i}=\alpha_{i} X+\varepsilon_{i} \\
Y=\sum_{i=1}^{n} \beta_{i} M_{i}+\tau^{\prime} X+\varepsilon
\end{gathered}
$$

where $\mathrm{i}=1 \ldots \mathrm{n}, \tau^{\prime}$ is the direct effect and $\tau$ is the total effect between the dependent variable and independent variable, $\alpha_{i} \beta_{i}$ is the indirect effect of each mediation path in Equation 17.

$$
\tau=\tau^{`}+\sum_{i=1}^{n} \alpha_{i} \beta_{i}
$$

The analysis of parallel multiple mediating effects generally includes three parts: first, the estimation and test of the overall mediating effect; second, the estimation and test of special mediating effects; third, the comparison between the mediating effects.

The total indirect effect is $\tau-\tau^{\prime}$, or $\sum_{i=1}^{n} \alpha_{i} \beta_{i}$. 
According to Mackinnon's suggestion (Mackinnon et al., 2007), the McGuigan and Langholtz effect size was to test the significance of the total indirect effect in Equation 18.

$$
t_{N-2}=\frac{\tau-\tau^{\prime}}{\sqrt{\sigma_{\tau}^{2}+\sigma_{\tau^{\prime}}^{2}-2 \rho_{\tau \tau^{\prime}} \sigma_{\tau^{\prime}} \sigma_{\tau^{\prime}}}}
$$

In the equation, $\sigma_{\tau}$ is the standard error of $\tau, \sigma_{\tau^{\prime}}$ is the standard error of $\tau^{\prime}$, and $\rho_{\tau \tau^{\prime}}$ is the regression coefficient between $\tau$ and $\tau$ '.

\section{Compound multiple mediation model}

The compound multiple mediations model is composed of the both parallel and serial mediating path see in Figure 3.

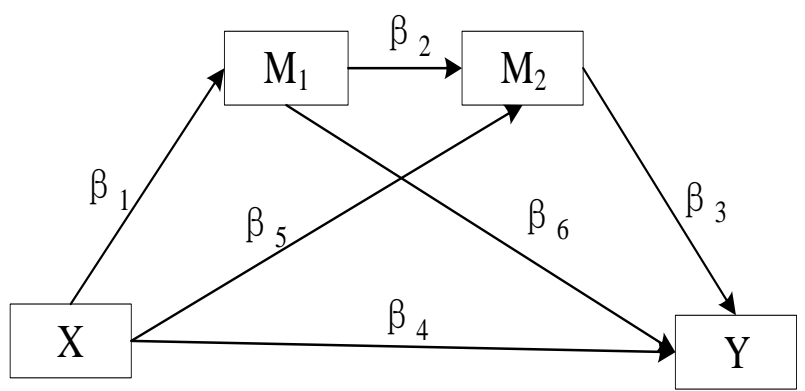

Figure 3 Compound multiple mediations model

To test the indirect effect, we need to estimate the following three equations (Eqs. 19-21).

$$
\begin{gathered}
M_{1}=\beta_{01}+\beta_{1}+\varepsilon_{1} \\
M_{2}=\beta_{02}+\beta_{2} M_{1}+\beta_{5} X+\varepsilon_{2} \\
Y=\beta_{03}+\beta_{4} X+\beta_{3} M_{2}+\beta_{6} M_{1}+\varepsilon_{3}
\end{gathered}
$$

\section{Results and analysis}

\section{Mediation test}

To test the significance of the indirect effect, the multivariate delta method, the unbiased estimate method, and the exact variance estimate method are used. The following is a brief introduction to the principle of these three methods.

\section{Multivariate delta method}

As can be seen above, $\beta_{1}, \beta_{2}$ and $\beta_{3}$ are the regression coefficients. The product of these three coefficients divides the mediation effect by the estimated standard error. The 
derivation of the three estimators of the variance of $\beta_{1}, \beta_{2}$ and $\beta_{3}$ are as follows in Equation 22.

$$
\begin{gathered}
s_{\text {multi }}^{2}=\left[\frac{\partial \beta_{1} \beta_{2} \beta_{3}}{\partial \beta_{1}}, \frac{\partial \beta_{1} \beta_{2} \beta_{3}}{\partial \beta_{2}}, \frac{\partial \beta_{1} \beta_{2} \beta_{3}}{\partial \beta_{3}}\right]\left[\begin{array}{ccc}
s_{\beta 1}^{2} & s_{\beta 1 \beta 2} & s_{\beta 1 \beta 3} \\
s_{\beta 2 \beta 1} & s_{\beta 2}^{2} & s_{\beta 2 \beta 3} \\
s_{\beta 3 \beta 1} & s_{\beta 3 \beta 2} & s_{\beta 3}^{2}
\end{array}\right]\left[\begin{array}{l}
\frac{\partial \beta_{1} \beta_{2} \beta_{3}}{\partial \beta_{1}} \\
\frac{\partial \beta_{1} \beta_{2} \beta_{3}}{\partial \beta_{2}} \\
\frac{\partial \beta_{1} \beta_{2} \beta_{3}}{\partial \beta_{3}}
\end{array}\right] \\
=\left[\beta_{2} \beta_{3}, \beta_{1} \beta_{3}, \beta_{1} \beta_{2}\right]\left[\begin{array}{ccc}
s_{\beta 1}^{2} & s_{\beta 1 \beta 2} & s_{\beta 1 \beta 3} \\
s_{\beta 2 \beta 1} & s_{\beta 2}^{2} & s_{\beta 2 \beta 3} \\
s_{\beta 3 \beta 1} & s_{\beta 3 \beta 2} & s_{\beta 3}^{2}
\end{array}\right]\left[\begin{array}{l}
\beta_{2} \beta_{3} \\
\beta_{1} \beta_{3} \\
\beta_{1} \beta_{2}
\end{array}\right] \\
=\beta_{2}^{2} \beta_{3}^{2} s_{\beta 1}^{2}+\beta_{1}^{2} \beta_{3}^{2} s_{\beta 2}^{2}+\beta_{1}^{2} \beta_{2}^{2} s_{\beta 3}^{2}+2 \beta_{1} \beta_{2} \beta_{3}^{2} s_{\beta 1 \beta 2} \\
+2 \beta_{1} \beta_{2}^{2} \beta_{3} s_{\beta 1 \beta 3}+2 \beta_{1}^{2} \beta_{2} \beta_{3} s_{\beta 2 \beta 3}
\end{gathered}
$$

In the compound multiple mediation model, $\beta_{1}, \beta_{2}$ and $\beta_{3}$ are independent, so the last three items are zero, and the variance in the multivariate delta estimate method is in Equation 23.

$$
s_{\text {multi }}^{2}=\beta_{2}^{2} \beta_{3}^{2} s_{\beta 1}^{2}+\beta_{1}^{2} \beta_{3}^{2} s_{\beta 2}^{2}+\beta_{1}^{2} \beta_{2}^{2} s_{\beta 3}^{2}
$$

\section{Unbiased estimate method}

The unbiased estimate method is based on the work of Goodman (1960). His research gives a suggestion for the calculation of unbiased estimate variance of two independent random variables. Extending his research to this case, the equation is in Equation 24.

$$
\begin{gathered}
s_{\text {unbiased }}^{2}=\left(\beta_{1}^{2}-s_{\beta 1}^{2}\right)\left(\beta_{2}^{2}-s_{\beta 2}^{2}\right) s_{\beta 3}^{2}+\left(\beta_{1}^{2}-s_{\beta 1}^{2}\right)\left(\beta_{3}^{2}-s_{\beta 3}^{2}\right) s_{\beta 2}^{2} \\
+\left(\beta_{2}^{2}-s_{\beta 2}^{2}\right)\left(\beta_{3}^{2}-s_{\beta 3}^{2}\right) s_{\beta 1}^{2}+\left(\beta_{1}^{2}-s_{\beta 1}^{2}\right) s_{\beta 2}^{2} s_{\beta 3}^{2} \\
+\left(\beta_{2}^{2}-s_{\beta 2}^{2}\right) s_{\beta 1}^{2} s_{\beta 3}^{2}+\left(\beta_{3}^{2}-s_{\beta 3}^{2}\right) s_{\beta 1}^{2} s_{\beta 2}^{2}+s_{\beta 1}^{2} s_{\beta 2}^{2} s_{\beta 3}^{2} \\
=\left(\beta_{1}^{2} \beta_{2}^{2} s_{\beta 1}^{2}-\beta_{1}^{2} s_{\beta 2}^{2} s_{\beta 3}^{2}+s_{\beta 1}^{2} s_{\beta 2}^{2} s_{\beta 3}^{2}-\beta_{2}^{2} s_{\beta 1}^{2} s_{\beta 3}^{2}\right)+\left(\beta_{1}^{2} \beta_{3}^{2} s_{\beta 2}^{2}\right. \\
\left.-\beta_{1}^{2} s_{\beta 3}^{2} s_{\beta 2}^{2}-\beta_{3}^{2} s_{\beta 1}^{2} s_{\beta 2}^{2}+s_{\beta 1}^{2} s_{\beta 2}^{2} s_{\beta 3}^{2}\right)+\left(\beta_{2}^{2} \beta_{3}^{2} s_{\beta 1}^{2}-\beta_{2}^{2} s_{\beta 3}^{2} s_{\beta 1}^{2}\right. \\
\left.-\beta_{3}^{2} s_{\beta 2}^{2} s_{\beta 1}^{2}+s_{\beta 1}^{2} s_{\beta 2}^{2} s_{\beta 3}^{2}\right)+\left(\beta_{1}^{2} s_{\beta 2}^{2} s_{\beta 3}^{2}-s_{\beta 1}^{2} s_{\beta 2}^{2} s_{\beta 3}^{2}\right)+\left(\beta_{2}^{2} s_{\beta 1}^{2} s_{\beta 3}^{2}\right. \\
\left.-s_{\beta 2}^{2} s_{\beta 1}^{2} s_{\beta 3}^{2}\right)+\left(\beta_{3}^{2} s_{\beta 1}^{2} s_{\beta 2}^{2}-s_{\beta 3}^{2} s_{\beta 1}^{2} s_{\beta 2}^{2}\right)+s_{\beta I}^{2} s_{\beta 2}^{2} s_{\beta 3}^{2} \\
=\beta_{1}^{2} s_{\beta 2}^{2} s_{\beta 3}^{2}+\beta_{1}^{2} \beta_{3}^{2} s_{\beta 2}^{2}+\beta_{2}^{2} \beta_{3}^{2} s_{\beta 1}^{2}-\beta_{1}^{2} s_{\beta 2}^{2} s_{\beta 3}^{2}-\beta_{2}^{2} s_{\beta 3}^{2} s_{\beta 1}^{2} \\
-\beta_{3}^{2} s_{\beta 1}^{2} s_{\beta 2}^{2}+s_{\beta 1}^{2} s_{\beta 2}^{2} s_{\beta 3}^{2}
\end{gathered}
$$




\section{Exact variance estimate method}

The exact variance estimate method is also an extension of Goodman's research. In this method, it draws into the square of the coefficient of variation to accomplish the calculation. For variable $\beta_{i}$, the function is in Equations 25 and 26.

$$
\begin{gathered}
G\left(b_{i}\right)=s_{\beta i}^{2} / \beta_{i}^{2} \\
s_{\text {exact }}^{2}=\left(\beta_{1} \beta_{2} \beta_{3}\right)^{2}\left[G\left(\beta_{1}\right)+G\left(\beta_{2}\right)+2 G\left(\beta_{3}\right)+2 G\left(\beta_{1}\right) G\left(\beta_{2}\right) G\left(\beta_{3}\right)\right. \\
\left.+G\left(\beta_{2}\right) G\left(\beta_{3}\right)\right] \\
=\left(\beta_{1} \beta_{2} \beta_{3}\right)^{2}\left[\frac{s_{\beta 1}^{2}}{\beta_{1}^{2}}+\frac{s_{\beta 2}^{2}}{\beta_{2}^{2}}+\frac{2 s_{\beta 3}^{2}}{\beta_{3}^{2}}+2 \times \frac{s_{\beta 1}^{2}}{\beta_{1}^{2}} \times \frac{s_{\beta 2}^{2}}{\beta_{2}^{2}} \times \frac{s_{\beta 3}^{2}}{\beta_{3}^{2}}+\frac{s_{\beta 2}^{2}}{\beta_{2}^{2}} \times \frac{s_{\beta 3}^{2}}{\beta_{3}^{2}}\right] \\
=\beta_{2}^{2} \beta_{3}^{2} s_{\beta 1}^{2}+\beta_{1}^{2} \beta_{3}^{2} s_{\beta 2}^{2}+\beta_{1}^{2} \beta_{2}^{2} s_{\beta 3}^{2}+\beta_{1}^{2} s_{\beta 2}^{2} s_{\beta 3}^{2}+\beta_{2}^{2} s_{\beta 3}^{2} s_{\beta 1}^{2} \\
+\beta_{3}^{2} s_{\beta 1}^{2} s_{\beta 2}^{2}+s_{\beta 1}^{2} s_{\beta 2}^{2} s_{\beta 3}^{2}
\end{gathered}
$$

According to Sobel's suggestion (Sobel, 1982), we calculate the confidence intervals for each method to test the significance of the model in Equation 27.

$$
95 \% \text { confidence interval }=\beta_{1} \beta_{2} \beta_{3} \pm z_{.975}\left(s_{\text {type }}^{2}\right)^{1 / 2}
$$

In the equation above, $z_{.975}=1.96$, and type is multivariate delta, unbiased or exact. The hypothesis can be confirmed when the $95 \%$ confidence interval does not include zero.

Table 2 shows the results for the methods. As the confidence interval of the model did not include zero, the hypothesis of this study was tested.

Table 2. Results for each method applied to data

\begin{tabular}{c|c|c|c|c}
\hline Method & Estimate & $\begin{array}{c}\text { Standard } \\
\text { error }\end{array}$ & Test & $\begin{array}{c}\text { Hypothesis test } \\
\text { result }\end{array}$ \\
\hline & $\beta_{1}=0.862$ & 0.071 & $\mathrm{~T}=12.074, \mathrm{P}<0.001$ & \\
Joint significance & $\beta_{2}=0.844$ & 0.055 & $\mathrm{~T}=15.428, \mathrm{P}<0.001$ & \\
& $\beta_{3}=0.589$ & 0.079 & $\mathrm{~T}=7.414, \mathrm{P}<0.001$ & Support hypothesis \\
\hline Multivariate delta method & $\beta_{1} \beta_{2} \beta_{3}=0.429$ & 0.08 & $95 \% \mathrm{Cl}=[0.272,0.586]$ & Support hypothesis \\
Unbiased estimate method & $\beta_{1} \beta_{2} \beta_{3}=0.429$ & 0.079 & $95 \% \mathrm{Cl}=[0.274,0.584]$ & Support hypothesis \\
Exact variance estimate method & $\beta_{1} \beta_{2} \beta_{3}=0.429$ & 0.084 & $95 \% \mathrm{Cl}=[0.264,0.594]$ & Support hypothesis \\
Percentile bootstrap & $\beta_{1} \beta_{2} \beta_{3}=0.429$ & - & $95 \% \mathrm{Cl}=[0.266,0.577]$ & Support hypothesis \\
Bias-corrected bootstrap & $\beta_{1} \beta_{2} \beta_{3}=0.429$ & - & $95 \% \mathrm{Cl}=[0.279,0.600]$ & Support hypothesis \\
\hline
\end{tabular}

\section{Optimal model selection}

By the comparison of the three multiple mediation models (see in Table 3), we found that the total indirect effect of the compound multiple mediation model was much better than the series multiple mediations model and parallel multiple mediation model. This 
indicates that the compound multiple mediation model was more suitable for the practical problem in this study.

Table 3. Comparison of three multiple mediation models

\begin{tabular}{c|c|c|c|c}
\hline Model & $\begin{array}{c}\text { Indirect } \\
\text { effect }\end{array}$ & $\begin{array}{c}\text { Standard } \\
\text { error }\end{array}$ & $\begin{array}{c}\text { Lower } \\
\mathbf{9 5 \%} \mathbf{C I}\end{array}$ & $\begin{array}{c}\text { Upper } \\
\mathbf{9 5 \%} \mathbf{C I}\end{array}$ \\
\hline Series multiple mediations model & 0.177 & 0.069 & 0.067 & 0.327 \\
Parallel multiple mediation model & 0.331 & 0.082 & 0.177 & 0.465 \\
Compound multiple mediation model & 0.509 & 0.057 & 0.407 & 0.606 \\
\hline
\end{tabular}

\section{Conclusion}

In this paper, we proposed a multiple mediation model to explore the relationship between low carbon economy and enterprise competitiveness. The results show that the low-carbon economy has a positive effect on technology innovation, and this effect will influence enterprise competitiveness through sustainable development. We also found that the compound multiple mediation model has more advantage to explain the problems involved with low carbon economy and enterprise competitiveness. Our finding has made an effective supplement to the study of low carbon economy and enterprise competitiveness theory. Therefore, in the future research on enterprise competitiveness, scholars should pay more attention to technological change and sustainable development to adapt to the low-carbon economy. For example, it is very important to explore how to balance the relationship between technological innovation and sustainable development.

\section{REFERENCES}

[1] Barron, A. R., Fawcett, A. A., Hafstead, M. A. C., Mcfarland, J. R., Morris, A. C. (2018): Policy insights from the EMF 32 study on U.S. carbon tax scenarios. - Climate Change Economics 9: 1840003.

[2] Du J., Li Q., Qiao F., Yu L. (2018): Estimation of vehicle emission on mainline freeway under isolated and integrated ramp metering strategies. - Environmental Engineering and Management Journal 17(5), 1237-1248.

[3] Ervine, K. (2018): How low can it go? Analysing the political economy of carbon market design and low carbon prices. - New Political Economy 23: 690-710.

[4] Foxon, T. J. (2011): A coevolutionary framework for analysing a transition to a sustainable low carbon economy. - Ecological Economics 70: 2258-2267.

[5] Garay, L., Font, X. (2012): Doing good to do well? Corporate social responsibility reasons, practices and impacts in small and medium accommodation enterprises. International Journal of Hospitality Management 31: 0-337.

[6] Glaser, M. (2003): Determinants of $\mathrm{CO}_{2}$ emissions in a small open economy'. Ecological Economics 45: 133-148.

[7] Gong, D., Liu, S., Tang, M., Ren, L., Liu, J. (2018): Revenue sharing or profit sharing? An internet production perspective. - Advances in Production Engineering \& Management 13(1): 81-92.

[8] Goodman, L. A. (1960): On the exact variance of products. - Publications of the American Statistical Association 55: 708-713.

[9] Healy, N., Barry, J. (2017): Politicizing energy justice and energy system transitions: Fossil fuel divestment and a "just transition" - Energy Policy 108: 451-459. 
[10] Hu, Z., Yuan, J., Hu, Z. (2011): Study on China's low carbon development in an economy-energy-electricity-environment framework. - Energy Policy 39: 2596-2605.

[11] Lefevre, J., Wills, W., Hourcade, J.-C. (2018): Combining low-carbon economic development and oil exploration in Brazil? An energy-economy assessment. - Climate Policy 18: 1286-1295.

[12] Li, J., Sun, C. (2018): Towards a low carbon economy by removing fossil fuel subsidies? - China Economic Review 50: 17-33.

[13] Louche, C., Busch, T., Crifo, P., Marcus, A. (2019): Financial markets and the transition to a low-carbon economy: Challenging the dominant logics. - Organization \& Environment 32: 3-17.

[14] Mackinnon, D. P., Fritz, M. S., Williams, J., Lockwood, C. M. (2007): Distribution of the product confidence limits for the indirect effect: Program PRODCLIN. - Behavior Research Methods 39: 384.

[15] Meeker, W. Q. J., Cornwell, L. W., Aroian, L. A. (1982): The Product of Two Normally Distributed Random Variables. - In: Kennedy, W. J., Odeh, R. E. (eds.) Selected Tables in Mathematical Statistics, Volume VII. American Mathematical Society, Providence, Rhode Island.

[16] Nader, S. (2009): Paths to a Low-Carbon Economy - The Masdar Example. - In: Gale, J., Herzog, H., Braitsch, J. (eds.) Greenhouse Gas Control Technologies 9. Proceedings of the 9th International Conference on Greenhouse Gas Control Technologies (GHGT-9), 16-20 November 2008, Washington DC, USA.

[17] Niamir, L., Filatova, T., Voinov, A., Bressers, H. (2018): Transition to low-carbon economy: Assessing cumulative impacts of individual behavioral changes. - Energy Policy 118: 325-345.

[18] Ortiz, O., Castells, F., Sonnemann, G. (2009): Sustainability in the construction industry: A review of recent developments based on LCA. - Construction \& Building Materials 23: 28-39.

[19] Preacher, K. J., Hayes, A. F. (2008): Asymptotic and resampling strategies for assessing and comparing indirect effects in multiple mediator models. - Behavior Research Methods 40: 879-891.

[20] Rijsberman, F. (2017): The key role of the meat industry in transformation to a lowcarbon, climate resilient, sustainable economy. - Meat Science 132: 2-5.

[21] Ropeik, D. (2017): Clean energy mind games if policy makers want to accelerate the transition to a low-carbon economy, they should heed the lessons of the decision sciences and take another look at nuclear energy. - Issues in Science and Technology 33: 59-64.

[22] Shimada, K., Tanaka, Y., Gomi, K., Matsuoka, Y. (2007): Developing a long-term local society design methodology towards a low-carbon economy: an application to Shiga Prefecture in Japan. - Energy Policy 35: 4688-4703.

[23] Smale, R., Hartley, M., Hepburn, C., Ward, J., Grubb, M. (2006): The impact of $\mathrm{co}_{2}$ emissions trading on firm profits and market prices. - Climate Policy 6: 31-48.

[24] Sobel, M. E. (1982): Asymptotic confidence intervals for indirect effects in structural equation models. - Sociological Methodology 13: 290-312.

[25] Tavoni, M., De Cian, E., Luderer, G., Steckel, J. C., Waisman, H. (2012): The value of technology and of its evolution towards a low carbon economy. - Climatic Change 114: 39-57. 